\title{
DIALÉTICA E ANALOGIA NA PAIDÉIA PLATÔNICA
}

Sérgio A. Sardj*

SÍNTESE - A analogia, enquanto procedimento metodológico da dialética platônica, estabelece uma relação entre paidéia e dialética ascendente. O presente estudo limita-se ao diálogo Ménon e visa, ainda, articular a relação entre este diálogo e o conjunto de obra de Platão no que concerne à relação entre analogia e dialética.
ABSTRACT - The analogy, as a methodological procedure of Plato's dialectic, establishes a relation between paidéia and ascendent dialectic. The present study is restricted to the Ménon and aims yet to connect it with Plato's entire work conceming the relation between analogy and dialectic.

Podemos encontrar, em toda a obra platônica, a utilização da analogia no interior da estrutura argumentativa dos diálogos. A analogia, utilizada como recurso pedagógico, consiste num procedimento metodológico, incluído no interior da dialética platônica, ${ }^{1}$ pela correlação que desenvolve com a mesma em termos da teoria do conhecimento e teoria do ser. O estudo da analogia poderá, portanto, nos esclarecer algo a respeito da relação entre ontologia e epistemologia, em Platão.

Neste texto, vamos analisar o exemplo do diálogo Ménon (71a-74b). O objetivo será o de - através da identificação de passagens do mesmo em que verifiquemos a utilização da analogia, enquanto procedimento metodológico pedagógico diferenciar os diversos modos de sua aplicação, bem como fornecer indicações para a sua conexão com o sentido mais amplo de dialética.

71b2-8 - "[...] e recrimino a mim mesmo o não saber nada acerca da virtude. E sem saber 0 que é, como será possivel conhecer suas qualidades ou caracteristicas? Acaso crês tu possível que alguém, sem saber quem é Ménon, saiba se é belo, rico e nobre, ou então se é tudo ao contrário? Te parece a ti possivel isso?"

* Professor do Instituto de Filosofia e Ciências Humanas da PUCRS e doutorando em Filosofia pela Unicamp/SP.

- Os procedimentos diairético e hipotético, o paradigma e a analogia e, no sentido da estrutura da argumentação, o próprio diálogo são procedimentos lógicos incluídos na dialética, embora não se confundam com a mesma. Compare Paviani, Jayme. A Dialética de Platão, as processos hipotéticos e diairéticos nos diálogos Paramênides, Sofista e Político, Projeto de pesquisa.

\begin{tabular}{|l|l|l|l|l|l|}
\hline VERITAS & Porto Alegre & v. 42 & $\mathrm{n}^{\mathbf{0}} 4$ & Dezembro 1997 & p. 923-929 \\
\hline
\end{tabular}


('I...) kai emautón katamémfomai hôs ouk eidoús peri aretês tó parápan' hó dé mê oída tí estin, pôs án opoión qé ti eideiên; Hê dokei soi oión te eínai, óstis Ménôna mê gignoúskei tó parápan óstis estín, toúton eidénai eíte kalós eíte kai gennaiós estin, eíte kai tanantia toútôn; Dokei soi oión t'einai;"'?

No texto sublinhado, temos a exposição de um princípio em sua formulação lógica; um principio universal e abstrato, i.é, não referido a nenhum caso específico.

No texto em negrito, temos a exposição do mesmo princípio em sua formulação analógica.

A formulação analógica de uma proposição de caráter universal consiste, assim, em Platão, em apresentar um "exemplo", uma situação particular, acessível ao conhecimento sensivel, a qual contenha semelhança com a formulação lógica; ao representar um caso particular que deve ser incluido no interior de uma relação universalmente expressa.

Observe-se, ainda, que a formulação lógica é, aqui, apresentada antes da analógica.

Assim, neste caso, a formulação analógica é exemplo, no sentido de ser um particular que indica um universal e, enquanto reproduz, ao nivel do sensivel as relações ideais, possibilita o trânsito do conhecimento de um a outro nível do ser, indicando um procedimento próprio da dialética ascendente.

Em 71e1-72a5 Ménon apresenta uma série de situações que visam definir a "virtude"; sua "definição" carece, no entanto, de uma unidade, um centro que as unifique. ${ }^{4}$ As situações apresentadas por Ménon, apesar de particulares e de fazerem referência ao sensível, não são analógicas. Aqui, o caso particular não conduz a um universal, não participa de um termo universal. Não são, assim, "exemplos", no sentido em que estabelecemos o termo; visam a ser a própria definição. $\mathrm{Na}$ passagem seguinte Platão utiliza-se, novamente, do recurso da analogia para poder estabelecer, no contexto do conhecimento sensível, o qual deve partir de uma multiplicidade, o sentido próprio de sua pergunta "o que é" (tí estín).

72a8-b6 - "Pois bem: seguindo esta imagem, suponhamos que te pergunte que é essencialmente uma abelha, e que tu respondes que elas existem de toda classe: que dirias tu ao perguntar-te eu se, quando afirmas que há grande número de abelhas de todas as classes e distintas umas das outras, queres dizer que elas são distintas enquanto abelhas, ou então queres dizer que o que as distingue não é mais que isto, por exemplo, a beleza, o tamanho e determinados caracteres do mesmo tipo? Dize-me, o que responderias a uma pergunta colocada desta forma?"

("Atár, ô Ménôn, katá taútên tén eikóna tén peri tá sménê, ei mou eroménon melittes perí ousías hó ti pot'estin, pollás kai pantodapás éleges autás eínai, ti án apekrinô moi, eí se êrómên' Ára toútôi fêis pollás kại pantodapás eivai kai diaferoúsas allêlôn, tôi melittas eínai; $\hat{E}$ toútôi mén oudén diaférousin. állôi dé tôi, oíon ê kállei ê megéthei ê állôi tôi toioútôn; Eipé, tí án apekrinô oútôs erôtêtheís;")

PLATÃO. Ménon. Ed. "Les Belles Lettres".

3 O que relaciona a analogia com o paradigma, utilizado, por exemplo, no Sofista, no caso da pesca com anzol.

4 72a "Sócrates - Na verdade, Ménon, tenho muita sorte: eu andava buscando uma virtude única e encontro em ti um exame de virtudes". 
Aqui, a formulação analógica de uma questão: a formulação analógica da pergunta pela essência.

Primeiramente, Platão sugere uma imagem, a qual resulta da crítica à falta de unidade daquilo que Ménon compreendia por "definição". A utilização da imagem, recorrente na obra platônica, insere-se, deste modo, no contexto mais amplo de sua dialética. $O$ estudo da relação entre a imagem e a estrutura tripartite da psikhê, bem como da questão de ser a imagem mediadora entre o sensivel e o inteligivel, insere-se na complexa dialética do ser e do não-ser, esboçada no Sofista, bem como da relação entre os níveis do ser e do conhecimento, problema que perpassa o conjunto da obra platônica, não podendo ser incluída nos limites deste estudo.

À pergunta de Sócrates, "colocada desta forma", Ménon responde:

72b9-10 - "Responderia, Sócrates, que, em minha opinião, enquanto abelhas não se diferenciam umas das outras."

("Tout'égôge, óti oudén diaférousin, hêi méllitai eisín, ê etéra tês etéras.")

A seguir, Sócrates estabelece a mesma pergunta em sua formulação lógica:

72c5-9 - "Pois bem: a pergunta é a mesma no que diz respeito às virtudes: por mui numerosas e distintas que sejam, têm em comum um determinado caráter geral que faz com que elas sejam virtudes. Esta caracteristica geral é o que se há de ter presente para que a resposta à pergunta seja correta e nos faça compreender em que consiste a virtude."

("Oútô dê kaí perí tôn aretôn' kai pantodapaí eisin, én gé tí eídos tautón ápasai échousin ${ }^{5}$ di'hó eisin aretaí, eis hó kalôs pou échei apoblépsanta tón apokrinómenon tôi erôtésanti ekeino dêlôsai hó tynchánei oúsa aretê'.")

É esta a forma da pergunta socrática. O modo como se apresenta, no Ménon, de Platão, a pergunta pela essência: a busca de um eídos, que unifica a multiplicidade. Isso relaciona diretamente o diálogo Ménon com o Sofista, entre outros.

Em função da problemática inerente à participação (metéxis, koinonía), ou seja, da relação entre as Idéias e o sensivel, a questão que nos surge é a que se na própria formulação da questão estaria presente a necessidade de uma "separação" daquilo que é "comum". Trata-se de que ao afirmar a existência de "[...] uma forma (eídos) que a todos contém [...]" expressa-se algo que ultrapassa a multiplicidade, interligando, unificando os diversos individuos externamente; a determinação de uma "característica geral" parece, portanto exigir uma "separação" do universal com relação aos indivíduos e das Idéias com relação ao sensivel. Tal formulação incluiria a necessidade de uma ousía exterior à multiplicidade que contém. Esta análise, no entanto, é insuficiente. A questão só poderá ser devidamente respondida com base numa investigação sobre o modo de apresentação, em Platão, das relações entre o individual (o múltiplo) e o universal (o uno), na totalidade de sua obra, relativamente à formulação de sua teoria do conhecimento.

Prossigamos na observação da utilização da analogia, por Platão, no Ménon.

Trad. (...uma forma - eídos- que a todos contém...). Ed Belle Letres: (...elles ont en commun un certain caractère géneral...). 
Após a afirmação, de Ménon, de que "[...] não capto, tão claramente como gostania o ponto exato da questão" ([...] ou méntoi ôs boúlomaí gé pô katéchô tó erôtoúmenón- 72d2-3), Sócrates irá utilizar-se de nova analogia, a qual, estendendo a mesma pergunta a outros objetos, visa conduzir Ménon a uma compreensão superior da mesma, o que equivaleria a transcender a esfera do sensível. A multiplicação de casos particulares, os quais mantêm um nexo entre si, conduz ao universal pela captação do próprio nexo que as unifica.

72d4-e1 - "É somente a virtude, Ménon, o que distingues desta forma, em virtude do homem, virtude da mulher, etc., ou então fazes tu as mesmas distinções a respeito da saúde, do tamanho, da força? Segundo teu modo de ver, é a saúde coisa distinta no homem e na mulher? Ou a saúde, onde quer que se encontre, não tem as mesmas características gerais, seja num homem ou em qualquer outro ser?"

("Póteron dé peri aretês mónon soi oútô dokeí, ô Ménôn, állê mén andrós eínai, állê dé gynaikós kaí tôn állôn, ê kai peri hygieías kaí peri megéthous kai peri ischýos ôsaútôs; Allê mén andrós dokeí soi eínai hygieia, állê dé gynaikós; $\hat{E}$ tautón pantachoú eidós estin, eán per hygieia êi, eán te en andri eán te en allôi otôioun êi;")

A dificuldade de Ménon consiste exatamente em captar este nexo, com relação à virtude:

73a4-5 - "Me parece, Sócrates, que este caso não é de modo algum idêntico ao anterior."

("Émoigé pôs dokei, ô Sôkrates, toúto oukéti omoion eínai toís állois toútois.")

Demonstra, então, Sócrates que, ao encontrarmos a virtude em duas espécies distintas, deveríamos poder encontrar em ambos as qualidades intrínsecas da virtude. Aqui, Platão estabelece, não uma formulação implícita do conceito de virtude, mas um procedimento analógico que visa estabelecer a conexão da Idéia de Virtude com as de Justiça e Prudência.

73a9-b7 - "Pois bem: administrar uma cidade ou uma casa ou qualquer outra coisa, não é por acaso administrá-la com prudência e com justiça?

- Sem dúvida.

- E administrar prudente e justamente não é fazê-lo com prudência e com justiça?

- Necessariamente.

- Por conseguinte, o homem e a mulher, para serem virtuosos, necessitam os dois das mesmas coisas, a justiça e a prudência."

("- Ár'oún oión te eú dioikein ê pólin ê oikian ê állo hotioún, mé sôfrónôs kai dikaiôs dioikoúnta;

- Ou dêta.

- Oukoún án per dikaiôs kai sôfrónôs dioikôsin, dikaiosýnêi kai sôfrosýnêi dioikésousin;

- Anánkê.

- Tôn autôn ára amfóteroi déontai, eíper méllousin agathoí einai, kai hê gyné kaí ho anér, dikaiosýnês kai sôfrosýnês.")

Num momento intermediário, estende a analogia às crianças e aos anciãos.

73b8-c3 "- É evidente.

- Se o menino e o ancião são desenfreados e injustos, acaso podem ser virtuosos?

- De nenhuma maneira.

- E se são prudentes e justos?

- Sim. 
- Assim, pois, todos os homens são virtuosos da mesma maneira, posto que são as mesmas qualidades que os fazem ser tais."

(“- Fainontai.

- Tí dé; Pais kai presbýtês môn akólastoi óntes kai ádikoi agathoi án pote génointo;

- Não certamente.

- Allá soúfrones kai díkaioi;

- Naí.

- Pántes ár'ánthrôpoi tôi autôi agathoí eisin' tôn autôn gär tychóntes agathoí gígnontai.")

Observemos tal momento intermediário, onde se opera a extensão da analogia aos meninos e anciãos. Aqui, a compreensão dos termos constituintes da virtude (a prudência e a justiça) se dão negativamente, o que inclui o problema de existirem Idéias também de termos negativos; esta questão não é tratada nos limites deste diálogo. Trata-se, neste contexto, de um procedimento dialético-dialógico, onde a compreensão do positivo opera-se via negatividade; além de transparecer aqui a maiêutica socrática, tal procedimento parece dever-se a que o significado do "nexo" que unifica os particulares possa ser assim melhor verificado na experiência.

A partir deste passo, o diálogo cede espaço a uma breve discussão de caráter ético-político; e é digno de nota que as discussões ético-políticas entremeiam a grande maioria dos diálogos, e parecem conter um motivo não explícito da argumentação. Isso se refere também ao Ménon. Sobre este prisma, seria interessante analisarmos o significado da inclusão posterior de um escravo no âmbito do diálogo.

A seguir, Sócrates irá utilizar-se da analogia para exemplificar o processo mesmo de "definir". Para determinar o que seja "definir" a virtude, dará exemplos de definições de outras coisas, partindo do exemplo do que seja um "universal".

73d9-e8 - "Realmente assim o creio, Sócrates, já que a justiça não é uma coisa distinta da virtude.

- Da virtude, Ménon, ou de uma virtude?

- Que queres dizer?

O que aplicaria eu também a outra coisa qualquer. Por exemplo, a propósito da redondez, se te parece, eu diria que é uma figura. E o diria assim porque há outras figuras além da redondez.

- Isto é falar corretamente, pois também eu reconheço que há outras virtudes além da justiça.

- Que virtudes? Dize-as da mesma maneira que eu te diria diversas classes de figuras se tu o pedisses: indica-me outras virtudes."

("- Oimai Égôge' hê gár dikaiosýnê, ô Soúkrates, aretê estin.

- Póteron aretê, ô Ménôn, ê aretê tis;

- Pôs touto légeis;

- Os peri állou otouoún. Oín, ei boúlei, strongylótêtos péri eipoim'án égôge óti schêmá tí estin, ouk oútôs aplôs óti schêma. Diá taúta dé oútôs án eipoimi, óti kai alla ésti schêmata.

- Orthôs ge légôn sý, epei kaí egó soi eípoimi án kaí álla schêmata, ei me keleúois’ kaí sý oún emoí eipé állas aretás.") 
A analogia visa reproduzir no ouvinte um modo de falar (epôs). Sócrates faz, assim, com que Ménon reconduza novamente a virtude a uma multiplicidade, para que então possa reencontrar um centro que a unifique. A diferença é que, neste passo, o diálogo já teria operado uma ascensão dialética, pois estaria já demonstrado haver um nexo que unifica os diversos particulares; trata-se, agora, que a "definição" de virtude deve poder distingui-la de seus termos constituintes (a justiça e a prudência). ${ }^{.}$A multiplicidade surge de uma maneira distinta, não mais referida diretamente ao sensivel.

74a7-b2 - "Eis aqui, Ménon, que encontramos de novo a mesma dificuldade, buscando uma virtude, encontramos várias, se bem que é verdade que de uma maneira distinta de antes. Em relação a esta virtude única que une entre si todas as demais, não chegamos a dar com ela.

- Te confesso, Sócrates, que esta virtude que tu buscas, esta virtude única, idêntica em todas as partes, não consigo concebê-la com tanta clareza como em teus demais exemplos."

(“- Pálin, ô Ménôn, tautón pepónthamen' pollás aú êyrékamen aretás miav tzêtoúntes, állon trópon ê nyndê' tén dé mian, ê diá pántôn toútôn estín, ou dunámetha aneureín. - Ou gár dýnamai pô, ô Sókrates, ôs sý tzêteís, mian aretên lábeín katá pántôn, ôsper en tois állois.")

Chegamos, por fim, a um ponto culminante de nossa argumentação, quando Platão fará referência a um processo comum de aprendizado (manthánou), o qual orienta a sua argumentação.

Prosseguirá utilizando-se da analogia, em todo este diálogo, inclusive na experiência com o escravo, o que nos conduz a uma anámnesis.

Isto será matéria de um próximo estudo.

A analogia assumirá, ainda, a forma de uma "argumentação por imagens", como na República, VI e VII.

Por ora, o fundamental é ressaitar que temos, com isso, em mãos, uma estratégia (entre outras possiveis) de leitura dos diálogos platônicos, que visa a explicitação de uma lógica implícita na estrutura de sua argumentação dialógica.

74b3-8 - "É muito natural. Vou, pois, esforçar-me, o quanto me é possível, a fim de poder seguir adiante. Tu compreendes já, sem dúvida, que o aprendizado em todas as partes é 0 mesmo. Imagina que alguém te propõe a questão de que falava eu antes: 'a que chamas tu figura, Ménon?' e que tu respondes: 'a redondez'; se então te perguntassem, como fiz eu, se 'a redondez é a figura ou uma figura', responderias evidentemente que é uma figura."

('Eikótôs ge' all'egô prothymêsomai, eán oiós t’ô, êmás probibásai. Mantháneis gár pou óti outôsi échei perí pantós' eí tís se anéroito toúto hó nyndê egô élegon, Tí estin schêma, ô Ménôn; ei autôi eipes óti strongylótês, eí soi eípen áper egô, Póteron schêma hê strongylótês estin ê schêma ti; eipes dêpou án óti schêmá ti. ")

- Observe-se que, no Sofista, Platão já havia determinado que a unidade de uma forma é exterior a seus elementos constituintes. 
Observamos, por fim, que o estudo dos procedimentos dialéticos, utilizados no contexto da dialética platônica, estabelece uma importante contribuição à investigação contemporânea acerca dos procedimentos pedagógicos, sobre o sentido da inclusão de tais procedimentos no interior de. uma teoria do conhecimento, bem como estabelece parâmetros para o exercício de uma reflexão crítica acerca da dimensão ético-política do ato de educar. O retorno aos clássicos não pode perder de vista a dimensão da possibilidade de uma retomada de posição acerca dos problemas vivenciados na contemporaneidade, sob pena de nos perdermos no puro academicismo. Destarte, espero que as considerações preliminares aqui apresentadas possam suscitar, mais que novas respostas, novas questões que impulsionem dialógica e dialeticamente a nossa reflexão filosófica. 